\section{Determination of the Volume and Weight of Living Animals}

WHEN accurate measurements of the weight of aquatic animals are necessary, most authors remove the adherent water by towelling the body with filter paper and woigh quickly and repeat until a constant weight is obtained. The method is defective since, apart from possible damage to the animals, the degree of dryness reached may not be the same each time. These difficulties increase when the animals are small and several have to be used at a time. Similarly, determinations of volume necessitate an elaborate procedure or the use of complicated apparatus.

For small marine Crustacea I find the following procedure better than the volumometer which I

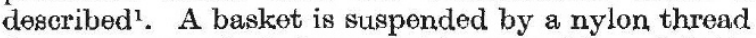
from one arm of a balance and immersed in a definite volume of sea-water in a beaker. The apparent weight of the basket and the thread is determined. The animals are then transferred to the basket and weighed. Next, a fourth of the sea water in the beaker is removed and distilled water is added, stirred and the animals weighed again. The animals are removed and the empty basket is weighed in the 75 per cent sea-water. The difference in apparent weights of the animals in sea-water of two densitios will thus help to calculate the volume of sea-water displaced and also the weight in air.

It has been found that determinations of apparent weight are not vitiated by osmotic transport, since most Crustacea take more than $10 \mathrm{~min}$. to respond to changes in media. This method is particularly suitable for making continuous observations on the rate of water transport in animals left in anisotonic media.

\section{P. Genanamuthu}

Department of Zoology,

University of Madras, India.

${ }^{1}$ Gnanamuthu, C. P., Nature, 170, 587 (1952).

\section{$\beta$-Galactosidase Changes in the Developing Intestinal Tract of the Rat}

IN some micro-organisms $\beta$-galactosidase (lactase) is an adaptive enzyme, that is, its biosynthesis is induced by external agents such as lactose or lactoserelated substances ${ }^{1}$. Apparently this is not the ease for the intestinal $\beta$-galactosidase of the rat, since a lactose-rich diet does not modify the intestinal specific activity ${ }^{2}$. In the work reported here, the behaviour of this enzyme has been investigated in the albino rat, starting from the last third of the intra-uterine life until adult age.

Homogenates of the small intestine from the duodenal flexure to the ileo-creal valve were used. The enzymo was determined by the ortho-nitrophenol released from the ortho-nitrophenyl- $\beta$-galactoside, at $38^{\circ} \mathrm{C}$. and $p \mathrm{H} 3 \cdot 5^{4}$. The ago of fotuses was estimated according to the histo-differentiation shown in the duodenal, ileo-creal and umbilical regions ${ }^{3}$, independently of the biochemical values. This technique allows a very close correlation between histological and biochemical data.

The changes in $\beta$-galactosidase activity during the end of pregnancy, new-born period and adult ago of the rat are plotted in Fig. 1.

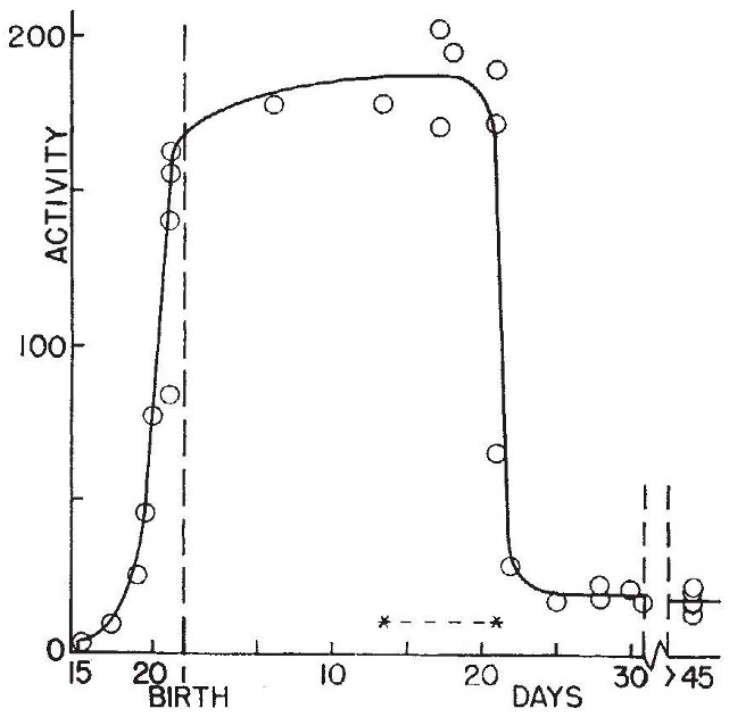

Fig. 1. Intestinal $\beta$-galactosidase activity expressed as $m \mu$ moles of ortho-nitrophenol released per mgm, of tissue (wet weight) in $1 \mathrm{hr}$ 22 days

The enzyme activity was also examined in different physiological and dietetic conditions : in adults on a lactose-rich diet, in pregnant rats, in nursing mothers, and in young rats kept after weaning on a complete diet with lactose (25-30 per cent) as the only carbohydrate (lactose-rich diet). The results are recorded in Table 1 together with the values for the normal adult and suckling rats.

Table 1. InTEstinal $\beta$-Galactosidase ACtivity ExpRessed as M $\mu$ MOLES ortho-NITROPHENOL RELEASED PER MGM. OF TISSUE (WET M $\mu$ MOLES ortho-NITROPHENOL RELEASED PER

\begin{tabular}{|c|c|c|c|c|}
\hline Diet & Condition & $\begin{array}{l}\text { No, of } \\
\text { animals }\end{array}$ & $\begin{array}{c}\beta \text {-galactosidase } \\
\text { activity }\end{array}$ & Incre \\
\hline ormal & Adult & 5 & $18 \pm 2 \cdot 9$ & $\times 1.00$ \\
\hline ormal & Pregnant & 4 & $18 \cdot 6 \pm 1.0$ & $\times 1.03$ \\
\hline Normal & Nursing & 3 & $18.4 \pm 2.4$ & $\times 1.02$ \\
\hline Mother's milk & 1-20 days old & 14 & $183 \pm 8.8$ & $\times 10.0$ \\
\hline & Adult & 3 & $19 \cdot 3 \pm 2 \cdot 1$ & $\times 1.07$ \\
\hline Lactos & $25-27$ days old & 3 & $19.8 \pm 3.0$ & $\times 1 \cdot 10$ \\
\hline
\end{tabular}

The features which became apparent from these results are: (1) The specific activity does not change on the diet rich in lactose (no induction in a strict sense), confirming discoveries of other authors ${ }^{2}$. (2) There are no significant changes either in the pregnancy or in the nursing period. (3) Activity inereases rapidly at the end of fotal life until birth, parallel to the very fast histo-differentiation of the digestive tract ${ }^{3}$. The high level remains rather constant in the new-born. (4) At the time of weaning (21-22 days) the activity decreases abruptly to the low adult-value. (5) This net decrease in the activity also occurs when the new-born is kept on the lactoserich diet.

Several authors have shown that lactose hydrolysis is necessarily previous to its intestinal absorption; the somewhat low $\beta$-galactosidase adult activity makes its action a limiting step in lactose assimilation, and therefore laxation and diarrhoea occur' ${ }^{2}$. An activity ten times higher in the new-born, as compared with the adult animal, is in agreement with the expected great efficiency as regards milk lactose assimilation in the sucklings. The "physiological 